\title{
THE
}

5-7-2015

\section{Contextual and Cultural Influences on Parental Feeding Practices and Involvement in Child Care Centers among Hispanic Parents}

Noereem Z. Mena

Kathleen S. Gorman

University of Rhode Island, kgorman@uri.edu

Katie Dickin

Geoffrey Greene

University of Rhode Island, gwg@uri.edu

Alison Tovar

University of Rhode.Island, alison_tovar@uri.edu Follow this and additional'works att: https://digitalcommons.uri.edu/nfs_facpubs

The University of Rhode Island Faculty have made this article openly available.

Please let us know how Open Access to this research benefits you.

This is a pre-publication author manuscript of the final, published article.

Terms of Use

This article is made available under the terms and conditions applicable towards Open Access Policy Articles, as set forth in our Terms of Use.

\section{Citation/Publisher Attribution}

Mena, N. Z., Gorman, K., Dickin, K., Greene, G., \& Tovar, A. (2015). Contextual and Cultural Influences on Parental Feeding Practices and Involvement in Child Care Centers among Hispanic Parents. Childhood Obesity, 11(4), 347-354. doi: 10.1089/chi.2014.0118

Available at: http://dx.doi.org/10.1089/chi.2014.0118

This Article is brought to you for free and open access by the Nutrition and Food Sciences at DigitalCommons@URI. It has been accepted for inclusion in Nutrition and Food Sciences Faculty Publications by an authorized administrator of DigitalCommons@URI. For more information, please contact digitalcommonsgroup@uri.edu. 
Contextual and cultural influences on parental feeding practices and involvement in childcare centers among Hispanic Parents

Noereem Z. Mena, MS, $\mathrm{RD}^{1 *}$ Kathleen Gorman, $\mathrm{PhD},{ }^{2}$ Kate Dickin ${ }^{3}$, Geoffrey Greene, $\mathrm{PhD},{ }^{1}$ Alison Tovar, $\mathrm{PhD}, \mathrm{MPH}^{1}$

${ }^{1}$ Department of Nutrition and Food Sciences, University of Rhode Island, Ranger Hall Kingston, Rhode Island, 02881, United States

${ }^{2}$ Department of Psychology, University of Rhode Island, Chafee Hall, Kingston, Rhode Island, 02881, United States

${ }^{3}$ Division of Nutritional Sciences, Cornell University, Savage Hall, Ithaca, New York, 14850, United States

*Corresponding author: Email mnoereem@gmail.com

Key Words: Feeding, Parents, Obesity, Children, Child-care, and Hispanic 
Background: Parental feeding practices shape children's dietary preferences and behaviors, which can influence a child's weight status. Limited research exists on the precursors and contextual influences of feeding, particularly among Hispanic parents. Therefore this study explored two areas potentially important for obesity prevention in young children: 1) precursors and contextual influences on parental feeding and 2) parental perceptions and knowledge of the child-care food environment.

Methods: Four focus groups ( $\mathrm{n}=36$ ) were held with Hispanic parents, predominantly mothers, of preschool children at two child-care centers. Parents were asked about influences on what and how they feed their children, awareness of the child-care center feeding environment, and current involvement in the child-care center. Themes were coded using NVivo10.

Results: Participants' childhood experiences influenced how they feed their children. Parents stated that both husbands and grandparents often indulged their children with unhealthy foods and thought this interfered with their efforts to maintain a healthy home environment.

Participants reported that what their children ate while in child-care sometimes influenced the home feeding environment.

Conclusion: Cultural and environmental factors influence parental feeding and involvement in the child-care setting. Consistent with socio-ecological system theory, exploring interactions between the environment and culture using a family-focus framework, such as the Family Ecological Model (FEM) could provide a better understanding of these influences among Hispanic parents. Future obesity prevention interventions with Hispanic families should be culturally relevant and target the different environments where children spend their time. 


\section{Introduction:}

Obesity among preschool children (2-5 years) in the United States (US) has nearly tripled over the last 30 years. ${ }^{1}$ Although obesity rates appear to be decreasing among this age group, ethnic disparities are evident whereby $17 \%$ of Hispanic children are obese compared to $3.5 \%$ of their white non-Hispanic counterparts. ${ }^{2}$ This is of concern, given that children who are overweight by age 5 are more susceptible to obesity later in life ${ }^{3}$ and that Hispanics are now the fastest growing and largest minority population in the US. ${ }^{4,5}$ Given that preschoolers are more likely to change behaviors compared to older children, ${ }^{6}$ early obesity prevention among Hispanic populations is critical.

Parents play a critical role in shaping children's dietary preferences and eating behaviors. $^{7-13}$ Overall, evidence suggests that both parental feeding practices (i.e. restriction, pressure to eat) and styles (i.e. authoritarian, indulgent) can negatively impact children's eating behavior and weight status. ${ }^{14-18}$ Although much of the literature has focused on white middleclass families, some studies have found that feeding practices may vary by socio-economic status (SES) and ethnicity. ${ }^{19-24}$ On one hand, restriction and pressure to eat has been found to be more common among low-income Hispanic mothers when compared to low-income non-Hispanic whites. ${ }^{25}$ On the other hand, Hispanic parents are also more likely to engage in permissive and indulgent feeding during meal times, compared to other racial and ethnic groups. ${ }^{21-23,25-29}$ Although these practices have been associated with unhealthy dietary and weight outcomes, there is limited evidence on what influences feeding practices, ${ }^{30,31}$ particularly among Hispanics. $^{19}$

In addition, the child feeding literature has focused primarily on parents and feeding within the home, ${ }^{31}$ but $60 \%$ of children in the US now spend some time in a child-care setting. ${ }^{32}$ 
This is important because growing evidence suggests that the child-care environment can influence positive and negative dietary behaviors in young children. ${ }^{33-37}$ Therefore, beginning to explore how the child-care food environment might influence the home feeding environment is of importance.

To help inform future obesity prevention efforts, cultural and environmental influences on parental feeding and involvement in child-care settings need to be better understood. ${ }^{38,39}$ Therefore the goals of this exploratory qualitative analysis were to explore: 1) precursors and contextual factors that influence parental feeding and 2) parental perceptions and knowledge of the child-care food environment. Given that there is limited research on this topic among Hispanic parents, qualitative exploratory methods were needed. Focus groups (rather than individual interviews) were selected as the most suitable approach to achieve the goal of generating discussions that would reveal perceptions and beliefs

\section{Methods:}

The Rhode Island Department of Education provided a list of six child-care centers that primarily served Hispanic families and participated in the United States Department of Agriculture Child and Adult Care Food Program. This federal program provides reimbursement for healthful meals and snacks served to low-income children and adults. ${ }^{40}$ Although center participation in this program is not a direct measure of income of the families they serve, it can be used as a proxy indicator of socioeconomic status. All six centers were contacted. Four directors responded and allowed parent recruitment to occur via flyers and during drop off and pick up. A total of 60 participants were approached among the four centers over a four-week period. "However, given the difficulty of recruiting at two centers (refusals and ineligibility), they were dropped from the study. A total of 40 participants were recruited from the remaining 
two centers. Eligibility criteria for participants included: 18 years or older, a child between the ages of 2-5, enrolled at the child care center, and self-identified as Hispanic/Latino ethnicity, and Spanish or English speaking.

Out of 40 participants recruited at the two centers, 36 caregivers (34 mothers, 2 grandmothers) participated in one of four English or Spanish focus groups. Three participants failed to attend and one was excluded from data analysis because they were not Hispanic/Latino. Trained bilingual/bicultural moderators guided the focus groups and an assistant moderator took notes, operated the digital recorder, and provided logistical support. The two focus groups conducted in Spanish were moderated by A.T., while N.M. served as the assistant moderator. N.M. moderated the English focus groups, while AT served as the assistant moderator. All focus groups were conducted in the early evening $(4.30-6 \mathrm{pm})$ and child-care was provided for the children in a separate room. Standard protocol was used to conduct these focus groups. ${ }^{41}$

Consent forms were reviewed and signed by the participants prior to the beginning of each focus group. All focus group were digitally recorded and lasted approximately 60 minutes and upon completion, participants completed a brief demographic survey. A $\$ 35$ incentive to a local super market was provided for participation. The study was reviewed and approved Institutional Review Board at the University of Rhode Island, Kingston, Rhode Island.

\section{Moderator Guide}

The content of the moderator guide used to lead the focus group discussions was informed by key informant interviews with directors, literature review, and discussions among study investigators. After multiple revisions, the guide was pilot tested with six women representing a similar demographic to our target population. Revisions were made to simplify language and improve cultural appropriateness of the questions. The guide was then reviewed 
with other colleagues and additional revisions were made. The moderator guide focused on four domains (Table 1). Domains were initially formulated to reflect the study aims and were revised as needed throughout the development of the moderator guide.

\section{Statistical Analysis}

The two researchers (N.M. and A.T.) met after each focus group to discuss initial findings and impressions. The Spanish audio recordings were translated and transcribed verbatim, simultaneously by a trained bilingual research team member. The English audio recordings were transcribed verbatim. NVivo (QSR) version 10 was used to assist in the organization of qualitative data for further analysis. All transcripts were read and reviewed by NM, who identified initial concepts and themes. ${ }^{41}$ Structural coding was used to categorize the data. Questions and key phrases from the moderator guide were used as structural codes. ${ }^{42}$ Using the structural codes, the transcripts were systematically reviewed. Text segments were then categorized into groups based on the moderator guide domains. Concepts and themes were then reviewed multiple times to ensure that all of the a priori and emergent themes were captured. Descriptive statistics were computed from the survey data, using SPSS version 22(IBM, Armonk, New York).

\section{Results:}

Of the 36 participating caregivers, $94 \%$ identified as mothers, and $31 \%$ identified as Dominican (Table 2). Over half of the participants (55\%) were non-US born but reported living in the US for an average of 14.5 years. Seventy-two percent of the participants were over 26 years old. Less than half reported being married and approximately $55 \%$ of the participants had at least some college education or a college degree or higher. The qualitative results are 
presented according to the moderator guide domains. Themes are incorporated within each domain.

\section{Factors that influence what and how parents feed their children}

\section{Childhood experience}

Participants' childhood experiences influenced how they feed their children. Many of them described that as children growing up, they weren't allowed to waste food in their household. Many shared stories about the "rule to finish your plate", and in some cases, that even meant that parents used physical force. The participants shared that the fear of "wasting food" was somehow ingrained in them. In contrast, many commented that they had made a conscious decision to use different feeding strategies with their own children:

“(My dad), he made us eat it and if we didn't eat it, he would spank us. But I learned that with my daughter I don't have to be like that."

This however could lead to feelings of guilt of wasting food:

“Sometimes I feel guilty because I don't want to push her to do anything she doesn't want to...I say sometimes am I horrible that I'm not pushing her to eat her plate? Like oh my

God, I'm wasting food! You know?"

One mother expressed how she would end up eating the leftovers her children would leave on their plates:

"I have to be honest because [although I don't do this anymore], last year I was at the point where my kids had to sit there and eat their food, because we were brought up that wasting food was a very bad thing, when others didn't have something to eat, you were just throwing it away...But I noticed I would end up eating all the leftovers, and that wasn't doing me any good." 


\section{Family health concerns}

Family health concerns, related to chronic disease, influenced what participants fed their children. The most common health concern was diabetes. For example, some participants mentioned not allowing sweets in the home environment or restricting how much and how often the children could have sweets:

"The sugar and the diabetes, because my mom has diabetes so that's kind of a concern in my family, so I try to watch out what my kids are getting as far as sugary foods."

and...

“...When people give me goodie bags I don't see it because I'm almost throwing it out the window... I just don't want my children to be diabetic like me. I wasn't born diabetic... if I could prevent it now that's what I want."

\section{Husband's food preferences}

Husband's food preferences influenced what was served to the child in the home, and often these preferences were reported to interfere with creating a more healthful food environment for themselves and their children:

“My meals consist of rice, beans, and meat because that is what my husband likes to eat."

In particular, mothers mentioned how their husband often modeled unhealthy behaviors, such as drinking soda, in front of their children:

"My husband is a soda fanatic...it was a struggle because I wouldn't let the girls drink it and they would want it, but every time they would see him with a glass of soda, if he wasn't looking, they would run and try to grab a sip... it's harder when everyone else around you is not on the same page." 


\section{Time and work schedules}

As expected, time and busy work schedules influenced parental feeding. The consensus was that home-cooked meals required a lot of time, and there just wasn't enough time in the day to fit in cooking.

\section{Grandparents}

A recurrent theme throughout the focus groups was how culture and bi-generational differences between the primary caregivers (mothers in majority of cases) and grandparents influenced what their children ate. The mothers in all of the focus groups expressed their struggle with their own parents when they fed their children non-traditional foods. One mother stated:

"When you take them to WIC, the nutritionist tells you what's healthier... so I go by [what she tells me]. My mom doesn't think I should because she goes back to 'oh she needs rice and beans"'.

All of the mothers agreed that grandparent's indulgent behaviors were an issue for them as it contradicted their efforts to promote healthy eating habits for their children:

"When my son goes to visit my parent's house, you've got the cookies, the juice, the cereals, the chocolate milk, the Oreos, whatever he wants, he gets. There's never a limit. So that's my struggle.

and...

"At los abuelos (grandparents)...it's horrible. I would have to tell them to stop giving him candy and junk food before meals...so basically we also have to be on top of other people letting them know, to avoid all that."

According to a few mothers, not indulging their grandchildren was taken very seriously by the grandparents and was even called abusive because eating sweets should be part of being a child. As one mother stated: 
“My family said that I was abusing her because I wouldn't let her eat sweets. I wouldn't let her eat doughnuts... I wouldn't let her drink soda. And they said that it wasn't fair, that every child should be able to have those kinds of things..."

\section{Awareness of the child-care center feeding environment \\ Parents are aware of the child-care feeding environment influences in the home}

Overall, the participants were aware of what foods were served at the center and thought that the foods served were healthy. They reported that the child-care environment had both positive and negative influences. Some reported that even though they did not purchase juice for their household, as a result of seeing other children drinking juice at the center, their children would ask for juice in the house and then would buy it:

"She started going to day care where there were older kids, and they drank juice. You know she sees them, and she wants juice... and so then I buy juice."

They voiced frustration over external influences and how this could lead to conflict around food even though they try to encourage healthy behaviors at home:

“...And even if I teach her right and she sees another kid doing something, she'll copy that behavior. So like as far as sugar and juice, I don't give her juice, but she's seen one person and that's my fight right now."

However, the child-care center also positively influenced what was eaten at home:

"At home when my son sees it (broccoli), he's like 'I want that', and I'm like "You eat that now?" And he's like 'Yeah they gave it to me at school'."

It was evident that the participants were also aware that their children would eat certain foods at the center and not in the home. They attributed this to peer influence. Many of the participants agreed when one of them stated:

"I think my daughter eats better here (child-care center) because she sees other kids eating. My daughter is an only child...I go home and I cook basically the same thing as 
here and she won't eat it. But then I ask the teacher if she ate yesterday and she's tell me

'Yeah! She ate well!' So I guess it's probably because she sees the other kids eating."

They stated that having a child-care center with healthy practices would influence their family choices and home environment. One participant responded: “...start doing it in the day care, it will be easier for us to give them those foods without them saying ew! Or, no! I don't want it!" when asked how they felt about the center serving more healthful foods like fruits and vegetables. Despite the positive aspects related to healthy changes at the center, some were not as enthusiastic; similar to one study, ${ }^{43}$ some of our participants did say that "healthy foods" were not "heavy" enough to sustain their children throughout the day. Some even believed that their children would lose weight and be more susceptible to getting sick, as one participated stated:

"But the problem is they start eating those foods (more healthy foods) and get used to that, they are going to lose weight. Imagine... they are going to get sick."

Interestingly, a few participants were concerned that their children were not being adequately fed during the day when at the child-care center. Some stated that portion sizes were too small compared to portions served at home. The following captures some of these concerns:

"I think mine is still hungry after she eats breakfast here because she is used to eating bigger portions at breakfast (at home)."

Despite their concerns over their children not being provided adequate amounts of food, many agreed that they did not follow-up with the child-care staff to confirm what and how much their children ate throughout the day. Many reported that although their children were most likely unreliable, they relied on them to provide diet information throughout the day, as many stated: " $I$ usually ask him/her if she ate and what she ate." 


\section{Current involvement in the child-care center}

\section{Parents want to be more involved in child-care center nutrition initiatives}

Participants expressed wanting to be actively involved in nutrition education programs at the child-care center. However, time constraints and hectic schedules were the major factors in preventing them from being more involved. As one participant expressed:

"Most of us, our kids are here because we are either working or in class, or we are doing something. So if they have activities during the daytime, I can't come. Sorry, you know? I can't miss a day of work, of class to come."

Given their busy work and family schedules they acknowledged barriers to in-person participation. They suggested the possibility of using email and text messages as alternatives as many reported using these frequently. The majority of the responses included: "Email's great!" and "Yeah text messages...that's easier for me." Some even suggested weekend workshops to attend with their children, a center blog where parents could view daily lesson plans, and tips on how to reinforce the lessons on different fruits and vegetables introduced at the center within the home.

\section{Discussion:}

The goals of our study were to explore precursors and contextual influences on parental feeding and parental perceptions/knowledge of the child-care food environment. We found that current feeding practices were influenced by past childhood experiences, cultural beliefs and current family health concerns. Participants also stated that external influences such as their children's peer interactions within the child-care center influenced the home feeding environment. Although participants described their awareness of healthy behaviors, they expressed that their efforts to provide a healthful feeding environment were often undermined by the grandparents' indulgence or father's preferences to eat unhealthy foods. Surprisingly, 
although many participants expressed concerns about diabetes, none of them mentioned obesity as a health concern in their family. The participants reported wanting to be more involved in the child-care center, however, as expected time constraints were the major barrier. These findings highlight the complex nature of a child's feeding environment and the need to intervene across multiple levels of influence.

Similar to another study, we found that childhood memories influenced current feeding practices with their own children. ${ }^{44}$ Although this study did not assess current feeding practices, participants reported use of less restrictive practices, such as allowing the child to decide when they had enough to eat, which may promote internal cues of hunger and satiety, contrary to outcomes associated with restrictive or controlling practices. ${ }^{8}$ Some participants however reported giving in to their children's request for candy and juice, which is consistent with more indulgent or permissive practices. These practices have not only been reported among Hispanics, but are also positively associated with child body weight. ${ }^{19,21-24,26}$

Mothers reported that their husbands' food preferences and poor dietary habits made it difficult for them to make positive dietary changes in the home. Although research with fathers has been limited, this is consistent with prior work in that fathers are less likely to monitor food intake and limit access to certain foods. ${ }^{45}$ To our knowledge the literature has predominantly focused on how maternal perceptions, knowledge, attitudes, beliefs, and diet influence child's health outcomes. ${ }^{46-49}$ Based on our findings, more research is needed to explore how spouses influence foods served and consumed in the home, which may affect the child's dietary intake.

In addition to spouses, findings from our study also suggest that grandparents' indulgent behaviors were perceived as a barrier to healthful dietary changes in the home. This is consistent with other studies in that parents and grandparents disagree about what foods their children 
should be eating. ${ }^{50-52}$ Grandparents appear to have just as much, if not more of an impact on child's dietary intake. ${ }^{51}$ Although the grandparents' indulgent behaviors may be associated with culture, whereby the concept of familismo (emphasis of familial interconnectedness and loyalty among family members), is prominent among Hispanics, ${ }^{53}$ it is possible that intergenerational differences such as grandparents' childhood experience and cultural beliefs related to healthy body size, exist. A study conducted among three-generation of Chinese families found that grandparents influenced young children's eating habits through the use of food to express their love. ${ }^{52}$ Their own experiences of poverty and cultural belief that obesity was a sign of health influenced their view of a "healthy child" ${ }^{52}$ These findings suggest that grandparents' influences on a child's feeding environment are not just limited to Hispanics, but other racial and ethnic families as well. However, it's important to note that a grandparents' occasional indulgence shouldn't be viewed as being only negative as grandparents' involvement has been associated with positive child outcomes. ${ }^{50}$ However, many of the participants in our study viewed it as a source of conflict suggesting an area to further investigate.

Given the central role that parents and families have in influencing a child's health within the Family Ecological Model (FEM), using this as a future theoretical framework could provide a better understanding of the cultural and environmental influences among Hispanic parents. Our findings support constructs within this model, ${ }^{54}$ for example, parents' childhood experiences and intergenerational influences on feeding are highlighted as well as the importance of family knowledge and social norms around food. Certain influences on child feeding, such as grandparents, may be specific to the Hispanic culture however. A future study should test a revised model adapted for Hispanic populations whereby the role of family is extended. 
Our findings are consistent with the prior literature in that a child's peer social network influences dietary behaviors. ${ }^{55}$ There is lack of evidence, however, on how a child's different environments are related or how environments influence interpersonal interactions such as childparent feeding. Future work may try to "bridge the gap" in continuity between the home and child-care environment in an effort to move towards adopting an ecological perspective on a child's dietary intake. ${ }^{33}$ It would be important to further explore how the child-care feeding environment influences child's diet quality in the home and vice-versa. As reported by Gubbels et al., studies that assess the influences on children's dietary behaviors and physical activity levels focus on either the home or the child-care environment. ${ }^{33}$ However, it is important to note that both the home and child-care environments influence children's behaviors related to weight status. ${ }^{56}$ Understanding that these two systems influence one another can help inform future interventions where consistency across environments is key.

It is interesting to note that although healthy eating was discussed, obesity did not come up as health concern for their families despite several prompts. This might suggest that our participants are not concerned with obesity but rather focusing on an overall healthy lifestyle. Also, some participants expressed fear that their kids could lose weight if they ate only healthy foods. This suggests that parents are concerned with undernutrition rather than overnutrition in their children, as parents not only in this study, but other studies as well, have expressed that a "skinny" child may be perceived by others as a sign of poor health and inadequate parenting. ${ }^{48,54}$ Perceptions on body weight may be influenced by acculturation, as one study found Mexican mothers in the US preferred to have a thinner child, compared to Mexican mothers living in Mexico. ${ }^{57}$ Over half of the participants in our study were non-US born; it is possible that these beliefs were associated with a less acculturated view on body weight which could in turn 
influence how they feed their children. It is also possible that these families are food insecure and are concerned about their children getting enough food.

Our study also reveals that parents want to be involved in nutrition programs in the childcare center but time and work schedules, as expected, were posed as major barriers. Given their enthusiasm to suggest alternative ways to be involved without in-person participation, further research should focus on more innovative ways to involve parents within the child-care setting, such as using blogs or other technology mediums like emails and text messages.

Nonetheless, our study is not without limitations. Although our study was meant to be inclusive of all parents and caregivers among this population, our participants were predominately women. In addition, we were only able to successfully recruit from two of the four centers; it is possible that parents from these centers are more involved and health conscious than those who are harder to reach. Gender roles are shifting, but mothers in this population continue to be primary caregiver and in charge of food preparation in the home. ${ }^{58,59}$ Our sample size was limited, and the majority of the women in our study who reported their ethnicity, identified as Dominican, thus findings may not be generalizable to other Hispanic or Latino subgroups. There is also the risk of self-selection bias at the center level and the possibility of a reduced diversity of views expressed due to the use of focus group discussions. ${ }^{54}$

\section{Conclusion}

Cultural and environmental factors influence parental feeding and involvement in the child-care setting. Future work should apply the $\mathrm{FEM}^{54}$ and adapt for use with Hispanic families in order to further understand different levels of these influences on parental feeding and involvement. Future obesity prevention interventions with Hispanic parents of young children should be culturally relevant and target different environments which children spend time in. 


\section{Acknowledgements}

This project was supported, in part, by the USDA National Institute of Food and Agriculture,

Hatch capacity grants, project \#RI00H-90, administered by the Rhode Island Agricultural

Experiment Station.

Author Disclosure Statement

No competing financial interests exist. 


\section{References:}

1. Center for Disease Control and Prevention. Trends in the Prevalence of Extreme Obesity Among US Preschool-Aged Children Living in Low-Income Families, 1998-2010. JAMA : the journal of the American Medical Association. 2012;398(24):2563-2565.

2. Ogden CL, Carroll MD, Kit BK, Flegal KM. Prevalence of childhood and adult obesity in the United States, 2011-2012. JAMA : the journal of the American Medical Association. Feb 26 2014;311(8):806-814.

3. Cunningham SA, Kramer MR, Narayan KM. Incidence of childhood obesity in the United States. The New England journal of medicine. Jan 30 2014;370(5):403-411.

4. Ennis S. R-VM, Albert N. 2010 Census Briefs: The Hispanic Population: 2010. US Census Bureau. 2010; http://www.census.gov/prod/cen2010/briefs/c2010br-04.pdf. Accessed October 10, 2013.

5. $\quad$ Passel JS, Cohn, D. U.S. Population Projections: 2005 - 2050. Pew Research Center;2008.

6. Wofford LG. Systematic review of childhood obesity prevention. Journal of pediatric nursing. Feb 2008;23(1):5-19.

7. Birch LL. Development of food preferences. Annual review of nutrition. 1999;19:41-62.

8. Birch LL, Fisher JO. Development of eating behaviors among children and adolescents. Pediatrics. Mar 1998;101(3 Pt 2):539-549.

9. Birch LS. Development of Food Acceptance Patterns in the First Years of Life. Proceedings of the Nutrition Society. 1999;57(4):617-624.

10. De Craemer M, De Decker, E., De Bourdeaudhuij, I., Vereecken, C., Deforche, B., Manios, Y., Cardon, G. Correlates of energy balance-related behaviours in preschool children: a systematic review. Obesity reviews : an official journal of the International Association for the Study of Obesity. Mar 2012;13 Suppl 1:13-28.

11. Golan M. Parents as agents of change in childhood obesity--from research to practice. International journal of pediatric obesity : IJPO : an official journal of the International Association for the Study of Obesity. 2006;1(2):66-76.

12. Hesketh KD, Campbell KJ. Interventions to prevent obesity in 0-5 year olds: an updated systematic review of the literature. Obesity. Feb 2010;18 Suppl 1:S27-35.

13. Lindsay AC, Sussner KM, Kim J, Gortmaker SL. The Role of Parents in Preventing Childhood Obesity. The Future of Children. 2006;16(1):169-186.

14. Fisher JO, Birch LL. Restricting access to palatable foods affects children's behavioral response, food selection, and intake. The American journal of clinical nutrition. Jun 1999;69(6):1264-1272.

15. Frankel LA, Hughes SO, O'Connor TM, Power TG, Fisher JO, Hazen NL. Parental Influences on Children's Self-Regulation of Energy Intake: Insights from Developmental Literature on Emotion Regulation. Journal of obesity. 2012;2012:327259.

16. Thompson AL, Adair LS, Bentley ME. Pressuring and restrictive feeding styles influence infant feeding and size among a low-income African-American sample. Obesity (Silver Spring, Md.). Mar 2013;21(3):562-571.

17. Kalinowski A, Krause K, Berdejo C, Harrell K, Rosenblum K, Lumeng JC. Beliefs about the role of parenting in feeding and childhood obesity among mothers of lower socioeconomic status. J Nutr Educ Behav. Sep-Oct 2012;44(5):432-437. 
18. Hughes SO, Power TG, Orlet Fisher J, Mueller S, Nicklas TA. Revisiting a neglected construct: parenting styles in a child-feeding context. Appetite. Feb 2005;44(1):83-92.

19. Hughes SO, Anderson CB, Power TG, Micheli N, Jaramillo S, Nicklas TA. Measuring feeding in low-income African-American and Hispanic parents. Appetite. Mar 2006;46(2):215-223.

20. Hughes SO, Shewchuk RM, Baskin ML, Nicklas TA, Qu H. Indulgent feeding style and children's weight status in preschool. Journal of developmental and behavioral pediatrics $\therefore J D B P$. Oct 2008;29(5):403-410.

21. Chaidez V, Townsend M, Kaiser LL. Toddler-feeding practices among Mexican American mothers. A qualitative study. Appetite. Jun 2011;56(3):629-632.

22. Melgar-Quinonez HR, Kaiser LL. Relationship of child-feeding practices to overweight in low-income Mexican-American preschool-aged children. Journal of the American Dietetic Association. Jul 2004;104(7):1110-1119.

23. Pesch MH, Harrell KJ, Kaciroti N, Rosenblum KL, Lumeng JC. Maternal styles of talking about child feeding across sociodemographic groups. Journal of the American Dietetic Association. Dec 2011;111(12):1861-1867.

24. Tovar A, Hennessy E, Pirie A, et al. Feeding styles and child weight status among recent immigrant mother-child dyads. The international journal of behavioral nutrition and physical activity. 2012;9:62.

25. Worobey J, Borrelli A, Espinosa C, Worobey HS. Feeding Practices of Mothers from Varied Income and Racial/Ethnic Groups. Early child development and care. Nov 1 2013;183(11):1661-1668.

26. Cardel M, Willig AL, Dulin-Keita A, Casazza K, Beasley TM, Fernandez JR. Parental feeding practices and socioeconomic status are associated with child adiposity in a multiethnic sample of children. Appetite. Feb 2012;58(1):347-353.

27. Martinez SM, Rhee K, Blanco E, Boutelle K. Maternal attitudes and behaviors regarding feeding practices in elementary school-aged Latino children: a pilot qualitative study on the impact of the cultural role of mothers in the US-Mexican border region of San Diego, California. Journal of the Academy of Nutrition and Dietetics. Feb 2014;114(2):230-237.

28. Olvera-Ezzell N, Power TG, Cousins JH. Maternal socialization of children's eating habits: strategies used by obese Mexican-American mothers. Child development. Apr 1990;61(2):395-400.

29. Turner BJ, Navuluri N, Winkler P, Vale S, Finley E. A qualitative study of family healthy lifestyle behaviors of Mexican-American and Mexican immigrant fathers and mothers. Journal of the Academy of Nutrition and Dietetics. Apr 2014;114(4):562-569.

30. Kremers S, Sleddens E, Gerards S, et al. General and food-specific parenting: measures and interplay. Childhood obesity. Aug 2013;9 Suppl:S22-31.

31. Patrick H, Hennessy E, McSpadden K, Oh A. Parenting styles and practices in children's obesogenic behaviors: scientific gaps and future research directions. Childhood obesity. Aug 2013;9 Suppl:S73-86.

32. US Department of Education, National Center for Education Statistics. (2013) Digest of Education Statistics, 2012 (NCES 2014-015), Chapter 2. 2012; http://nces.ed.gov/fastfacts/display.asp?id=4. Accessed April 23, 2013, 2013.

33. Gubbels JS, Van Kann DH, de Vries NK, Thijs C, Kremers SP. The next step in health behavior research: the need for ecological moderation analyses - an application to diet 
and physical activity at childcare. The international journal of behavioral nutrition and physical activity. 2014;11:52.

34. Hughes SO, Patrick H, Power TG, Fisher JO, Anderson CB, Nicklas TA. The impact of child care providers' feeding on children's food consumption. Journal of developmental and behavioral pediatrics : JDBP. Apr 2007;28(2):100-107.

35. Erinosho T, Dixon LB, Young C, Brotman LM, Hayman LL. Nutrition practices and children's dietary intakes at 40 child-care centers in New York City. Journal of the American Dietetic Association. Sep 2011;111(9):1391-1397.

36. Benjamin Neelon SE, Vaughn A, Ball SC, McWilliams C, Ward DS. Nutrition practices and mealtime environments of North Carolina child care centers. Childhood obesity. Jun 2012;8(3):216-223.

37. Copeland KA, Benjamin Neelon SE, Howald AE, Wosje KS. Nutritional quality of meals compared to snacks in child care. Childhood obesity. Jun 2013;9(3):223-232.

38. Rodriguez-Oliveros G, Haines J, Ortega-Altamirano D, et al. Obesity determinants in Mexican preschool children: parental perceptions and practices related to feeding and physical activity. Archives of medical research. Aug 2011;42(6):532-539.

39. Skala K, Chuang RJ, Evans A, Hedberg AM, Dave J, Sharma S. Ethnic differences in the home food environment and parental food practices among families of low-income Hispanic and African-American preschoolers. Journal of immigrant and minority health / Center for Minority Public Health. Dec 2012;14(6):1014-1022.

40. USDA. Child and Adult Care Food Program (CACFP). http://www.fns.usda.gov/cacfp/child-and-adult-care-food-program. Accessed Dec 19, 2013.

41. Krueger RA, \& Casey, M. A. (Eds.), ed Focus groups: A practical guide for applied research. Third ed. California: Sage Publications; 2000. Oaks T, ed.

42. Guest G, MacQueen, Kathleen and Namey, Emily. Applied Thematic Analysis. Sage; 2011.

43. Benjamin SE, Haines J, Ball SC, Ward DS. Improving nutrition and physical activity in child care: what parents recommend. Journal of the American Dietetic Association. Nov 2008;108(11):1907-1911.

44. Malhotra K, Herman AN, Wright G, Bruton Y, Fisher JO, Whitaker RC. Perceived benefits and challenges for low-income mothers of having family meals with preschoolaged children: childhood memories matter. Journal of the Academy of Nutrition and Dietetics. Nov 2013;113(11):1484-1493.

45. Khandpur N, Blaine RE, Fisher JO, Davison KK. Fathers' child feeding practices: A review of the evidence. Appetite. Mar 22 2014;78C:110-121.

46. Baughcum AE, Chamberlin LA, Deeks CM, Powers SW, Whitaker RC. Maternal perceptions of overweight preschool children. Pediatrics. Dec 2000;106(6):1380-1386.

47. Brown JE, Broom DH, Nicholson JM, Bittman M. Do working mothers raise couch potato kids? Maternal employment and children's lifestyle behaviours and weight in early childhood. Social science \& medicine. Jun 2010;70(11):1816-1824.

48. Killion L, Hughes SO, Wendt JC, Pease D, Nicklas TA. Minority mothers' perceptions of children's body size. International journal of pediatric obesity : IJPO : an official journal of the International Association for the Study of Obesity. 2006;1(2):96-102.

49. Lindsay AC, Sussner KM, Greaney ML, Peterson KE. Influence of social context on eating, physical activity, and sedentary behaviors of Latina mothers and their preschool- 
age children. Health education \& behavior : the official publication of the Society for Public Health Education. 2009;36:81-96.

50. Pulgaron ER, Patino-Fernandez AM, Sanchez J, Carrillo A, Delamater AM. Hispanic children and the obesity epidemic: exploring the role of abuelas. Families, systems \& health : the journal of collaborative family healthcare. Sep 2013;31(3):274-279.

51. Roberts MaPS. The Influence of Grandparents on Children's Diets. Journal of Research for Consumers. 2010(18).

52. Jiang J, Rosenqvist U, Wang H, Greiner T, Lian G, Sarkadi A. Influence of grandparents on eating behaviors of young children in Chinese three-generation families. Appetite. May 2007;48(3):377-383.

53. Steidel AGL, Contreras JM. A new familism scale for use with Latino populations. Hispanic J Behav Sci. Aug 2003;25(3):312-330.

54. Davison KK, Jurkowski JM, Lawson HA. Reframing family-centred obesity prevention using the Family Ecological Model. Public health nutrition. Oct 2013;16(10):1861-1869.

55. Salvy SJ, de la Haye K, Bowker JC, Hermans RC. Influence of peers and friends on children's and adolescents' eating and activity behaviors. Physiology \& behavior. Jun 6 2012;106(3):369-378.

56. Kremers SP. Theory and practice in the study of influences on energy balance-related behaviors. Patient education and counseling. Jun 2010;79(3):291-298.

57. Rosas LG, Harley KG, Guendelman S, Fernald LC, Mejia F, Eskenazi B. Maternal perception of child weight among Mexicans in California and Mexico. Maternal and child health journal. Nov 2010;14(6):886-894.

58. Galanti GA. The Hispanic family and male-female relationships: an overview. Journal of transcultural nursing : official journal of the Transcultural Nursing Society / Transcultural Nursing Society. Jul 2003;14(3):180-185.

59. Raffaelli M, Ontai LL. Gender socialization in Latino/a families: Results from two retrospective studies. Sex Roles. Mar 2004;50(5-6):287-299. 